\title{
Сьюзен Басснетт
}

\section{ИСТОКИ И РАЗВИТИЕ ПЕРЕВОДОВЕДЕНИЯ В 1975-2016 гг. ${ }^{1}$}

Уорикский университет, Ковентри, CV4 7AL, Великобритания

Университет Глазго, Глазго G12 8QQ, Великобритания

В статье рассматриваются истоки переводоведения, начиная с первых заседаний Левенской группы в 1970-х годах по настоящее время, с целью показать, как эта область науки превратилась в явление международного масштаба. В течение десятилетий с тех пор, как Дж. Холмс впервые предложил термин «переводоведение» (Translation Studies), наблюдался постепенный отход от сугубо лингвистической концепции перевода к современной интерпретации его как инструмента межкультурного общения. В статье исследуется, как повлияло на развитие переводоведения обращение к культурному аспекту перевода, выдвинутому С. Басснетт и А.Лефевром в начале 1990-х годов, и анализируется воздействие на переводоведение идей постколониализма, феминизма, социологии, а также последних достижений сопоставительного литературоведения и истории всемирной литературы. Доказывается, что в 1980-е годы имела место консолидация сил в переводоведении, а в 1990-е годы эта наука распространилась по всему миру. В XXI в. наблюдается дальнейшее расширение диапазона исследований, в частности в области аудиовизуального, медийного и новостного перевода. Обращается внимание на изменение отношения к переводу и созидательной роли переводчика, в том числе на сближение деятельности переводчика с оригинальным литературным творчеством. Библиогр. 32 назв.

Ключевые слова: переводоведение, полисистемная теория, культурный переворот, переводчик, творческая деятельность.

\section{THE ORIGINS AND DEVELOPMENT OF TRANSLATION STUDIES 1975-2016}

\section{Susan Bassnett}

The University of Warwick, Coventry CV4 7AL, United Kingdom

University of Glasgow, Glasgow, G12 8QQ, Scotland

This essay traces the origins of Translation Studies from the early meetings of the Leuven group in the 1970s to the present, showing how from humble beginnings the field has become a world-wide phenomenon. Through the decades since the term 'Translation Studies' was first coined by James Holmes, there has been a shift of emphasis away from a narrowly defined linguistic notion of translation to the present conception of translation as an intercultural exchange. The essay looks at the impact of the cultural turn proposed by Susan Bassnett and Andre Lefevere in the early 1990s, showing how translation studies came to diversify through contacts with postcolonial theory, feminist and gender theory, sociological theory and recent developments in comparative and world literature. It is argued that while the 1980s was a decade of consolidation for Translation Studies, the 1990s was the decade of global expansion of the field. The twenty-first century has seen further expansion, with the growing importance of research into audiovisual translation, media translation, and global news translation. The essay also considers changing attitudes to translation and to the creative role of the translator, showing the current synergies between translation and creative writing. Refs 32 .

Keywords: Translation Studies, polysystems theory, cultural turn, translator, creative writing.

\section{Введение}

Перевод как литературное творчество существует уже много тысячелетий, но систематическое изучение его в качестве научного предмета началось сравнительно недавно. В течение нескольких последних десятилетий область науки,

\footnotetext{
1 Пер. с англ. Т. Казаковой.

(c) Санкт-Петербургский государственный университет, 2016
} 
известная как переводоведение, развивалась стремительно по экспоненте, в результате чего появилось огромное множество книг, статей, журналов, материалов конференций, академических программ, научно-исследовательских связей и получивших масштабную финансовую поддержку научных проектов, а термин «переводоведение» (Translation Studies) признан во всем мире. Большая часть результатов этой деятельности стала известна на английском языке, но следует отметить также, что развивалась и влиятельная немецкая традиция Übersetzungwissenschaft (наука о переводе), а также traductologie (переводоведение) во Франции. Быстрыми темпами развивается сравнительно молодое переводоведение в Китае, отвечая потребностям в международном общении. В целом изучение перевода, которое многие рассматривают как самостоятельную область науки, распространилось по всему миру.

Развитие переводоведения в англоязычном мире, в частности в Британии, Ирландии, Канаде, Индии, Южной Африке, Гонконге и, в меньшей степени, в США, может на первый взгляд показаться удивительным, учитывая тот факт, что на английский язык переводится гораздо меньше материала, чем на другие языки. Отчасти это объясняется тем, что, как будет показано далее, исследования развивались независимо от лингвистического подхода к переводу и программам подготовки переводчиков, который преобладал во многих странах Европы и Азии. Переводоведение теперь входит в программы по сравнительному литературоведению и особенно быстро растущей области истории всемирной литературы. Одним из самых полезных учебников, предназначенных для ознакомления студентов с этой стремительно развивающейся отраслью, стала книга Дж. Мандея Introducing Translation Studies. Theories and Applications («Введение в переводоведение. Теория и практика»), впервые опубликованная в 2001 г. и теперь вышедшая в третьем издании (2013). Мандей делает обзор лингвистических подходов, рассматривает функциональные теории, дискурсивно-стилистические модели, системный анализ, философский аспект и роль новейших мультимедийных технологий, а также предлагает обширный список литературы. В этом учебнике отражено многообразие подходов, действующих в данной области.

\section{Истоки переводоведения}

Термин «переводоведение» (translation studies) был введен в 1970-е годы американским переводчиком и теоретиком, жившим в Голландии, Джеймсом Холмсом. В статье “The Name and Nature of Translation Studies” («Название и содержание переводоведения»), впервые опубликованной в 1972 г., Холмс указал на то, что в течение многих веков в англоязычном мире перевод удостаивался лишь «отрывочных упоминаний в трудах писателей, филологов и литературоведов да изредка в работах какого-нибудь лингвиста», но после Второй мировой войны наблюдается растущий интерес к проблемам перевода [Holmes, 2000, p. 173]. Многие также отмечают, что подобный интерес к переводу, видимо, связан с утопическим представлением об идеальном, совершенном переводе, который мог бы достигаться с помощью новых технологий, что было обусловлено достижениями в области дешифровки и помогло союзным государствам победить Германию. Холмс рассматривает окончание Второй мировой войны как поворотный пункт, когда стало ясно, что у машинного 
перевода имеются многие ограничения, что, в свою очередь, привело к осознанию сложности переводческого процесса, причем сложности не только сугубо лингвистической, но и стилистической и культурной. На сегодняшний день, с учетом всех невероятных достижений в машинном переводе, особенно в корпусной лингвистике, можно отметить, как далеко мы продвинулись в понимании и программировании процесса перевода. Тем не менее не следует забывать о том скептическом отношении к машинному переводу, которое имело место в 1970-е годы.

Очерчивая контуры той области, которая стала известна как «переводоведение», Холмс выдвинул три направления исследований: во-первых, дескриптивный подход, призванный описать известные факты перевода, как они есть; во-вторых, теоретический подход, призванный выяснить принципы, объясняющие эти факты; и, в-третьих, прикладной подход, который смог бы на основе данных, полученных с помощью первых двух, способствовать практическому переводу и подготовке переводчиков.

Идеи Холмса были предложены небольшой группе ученых из Израиля, Голландии, Бельгии, Словакии (тогда в составе Югославии), сложившейся в начале 1970-х годов. В группу входили: Итамар Эвен-Зохар, Хосе Ламбер, Гидеон Тури, Андре Лефевр, Реймонд ван де Брук и Антон Попович; в результате плодотворной работы на семинаре 1976 г., когда к группе присоединилась Сьюзен Басснетт, была предпринята попытка сформулировать некий манифест о формирующейся новой, с их точки зрения, науке. Этот манифест, написанный Лефевром, был опубликован вместе с материалами семинара в 1978 г. и включал формулировку задач новой науки: «Цель данной науки заключается в разработке комплексной теории, которую можно было бы применить в качестве основы для практики перевода. Эта теория окажется полезной благодаря аргументации, не сводимой ни к неопозитивистским, ни к герменевтическим основаниям [Lefevere, 1978, p. 234].

Теорию предполагалось проверять на практических приложениях, чтобы она стала не статичной, а динамичной. Выступая на встречах группы, Лефевр предостерегал от того, что он называл пустыми терминологическими пререканиями, поскольку гораздо важнее разработать основы новой науки о переводе, направленной на решение конкретных переводческих проблем, которая бы не замыкалась в себе, а была доступной (инклюзивной, а не эксклюзивной). Имея в виду доступность, оказалось важным разработать для обсуждения проблем перевода такой язык, который был бы понятен не только узкой группе ученых, занятых собственными теориями и общающихся друг с другом на ученом жаргоне, но был бы понятен и действующим переводчикам. Заключительное слово Лефевра сегодня звучит как пророчество: «Вполне вероятно, что теория, разработанная таким образом, может оказаться полезной для развития лингвистики и литературоведения; также вероятно и то, что переводы, выполненные в соответствии с предложенными нами принципами, могут внести вклад в развитие принимающей культуры» [Lefevere, 1978, p. 235].

Оглядываясь назад, можно отметить согласованность разных, но все же в чемто совместимых идей, возникшую в процессе осознания обстоятельств, приведших к регулярным встречам группы ученых, чаще всего называемой Левенской группой - по имени места, где в 1976 г. проводился семинар, или Полисистемной группой - в связи с использованием теории полисистем с самого начала дискуссий. 
Конечно, важную роль сыграли идеи русских формалистов и пражских структуралистов, которые в то время только осваивались в англоязычном мире и звучали в унисон с такими англосаксонскими движениями, как Новая критика в США и техника внимательного чтения, разработанная британскими учеными У.Эмпсоном и А.А.Ричардсом. Различие заключается в том, что в начале 1970-х годов англосаксонский мир был решительно настроен против теоретизирования, тогда как Левенская группа основывалась на теориях, разработанных в литературоведении, лингвистике и философии. Важно отметить и то, что преимущественным интересом Левенской группы, в отличие, например, от немецких коллег, был литературный перевод.

\section{Период развития: 1980-е годы}

К середине 1980-х годов термин «переводоведение» получил широкое распространение и начал наполняться собственным содержанием. Вехами стали публикации книги Г. Тури “Descriptive Translation Studies and Beyond” («Дескриптивное переводоведение и за его пределами») (1985) и сборника статей под редакцией Т. Херманса “The Manipulation of Literature” («Манипулирование в литературе») (1985), включавшего работы многих членов Левенской группы, благодаря которому вошел в обиход термин «Манипулятивная школа». В период 1980-х годов активно изучалась история перевода в различных культурах, ибо научный проект Левенской группы требовал обращения к истории перевода и смены эстетических критериев. Это впоследствии приведет к выходу наиболее значительного труда Г. Тури, посвященного понятию переводческих норм. В статье 1985 г. "A Rationale for Descriptive Translation Studies” («Основы дескриптивного переводоведения») Тури доказывает, что нельзя продуктивно анализировать отдельные переводы без обращения к другим переводам в рамках общей литературной традиции. Он отмечает, что такой анализ должен проводиться на микро- и макроструктурном уровне, и считает, что хотя вполне допустим анализ единичных переводов и отдельных переводчиков, но недопустимо «не учитывать тот факт, что данный перевод или данный переводчик так или иначе связан с другими переводами и переводчиками» [Toury, 1985b, p.51]. С его точки зрения, составной частью анализа перевода должно быть сопоставление и обращение к культурному контексту. В этом смысле его идеи близки высказанным его соотечественником Эвен-Зохаром, который искал ответы на такие вопросы, как: почему те или иные культурные традиции обращаются к переводу чаще или реже в разные периоды; какие условия способствуют или препятствуют переводческой деятельности; как отбираются тексты для перевода; почему одни переводы удаются, а другие терпят неудачу; можно ли распознать и составить схему переводческой деятельности.

Другой точкой соприкосновения в рамках Левенской группы послужило общее недовольство тем маргинальным положением, которое отводят переводу лингвисты и литературоведы. Для литературоведения характерно негативное суждение о переводе как обязательно «неверном», а также убеждение в том, что перевод всегда уступает оригиналу, а статус переводчиков ниже статуса «оригинальных авторов»; и вообще задача переводчика сводится к созданию точной копии оригинала, и т. п. В лингвистике суждения о переводе строятся в условиях деконтекстуализа- 
ции или формулируются в абстрактных научных терминах. В связи с этим одной из первых забот новорожденного переводоведения стал вызов традиционным представлениям об эквивалентности. Холмс был привычно откровенен в высказывании своих взглядов. Он предположил, что если пяти переводчикам дать простое, не связанное метрическими рамками стихотворение, то вряд ли даже два из пяти переводов окажутся одинаковыми. Далее, если взять пять групп по пять переводчиков в каждой и предложить им сделать обратный перевод этого стихотворения, в результате «почти наверняка получится столько же разных текстов, сколько самих переводчиков. Называть это эквивалентностью некорректно» [Holmes, p. 53].

Указывал на невозможность полной эквивалентности в переводе и А.Попович, учитывая семантические и структурные различия между языками; в статье, озаглавленной “The Concept of 'Shift of Expression' in Translation Analysis” («Понятие “сдвига высказывания” в анализе перевода»), он прозорливо замечает, что переводчик имеет естественное право не зависеть от оригинала и изменять его. Сегодня эта идея не выглядит чем-то необычным, но в 1970-е годы она звучала поистине радикально. Попович также настаивал на большем внимании к таким историческим обстоятельствам, как изменение требований и литературных норм. В течение 1980-х годов активно изучалась история перевода как в плане переводческой деятельности, так и в плане восприятия переводов в иноязычных литературных традициях.

В весьма полезной книге “Contemporary Translation Theories” («Современные теории перевода») (1993; 2001) Э. Гентцлер прослеживает разнообразные пути, которые ведут к возобновлению интереса к переводу. Будучи представителем американской традиции семинаров по литературному творчеству, он видит в ней как возможность обсудить важные вопросы, так и воспитать плеяду блестящих переводчиков вроде Дж. Фелстинера, Д. Уайсброта, У. Мервина или Ф. Уилла, но отмечает весьма слабый интерес к теории перевода. Он обращает внимание на влиятельные немецкие школы, которые привели к формированию функциональной skoposтеории, разработанной Г. Фермеером и К. Райсс, а в последнее время и к солидной работе, проделанной К. Шефнер и ее коллегами по изучению роли политического дискурса в переводе, но в основном сосредоточивается на достижениях полисистемной группы, в частности на новаторском труде И.Эвен-Зохара: «Расширяя теоретические горизонты традиционной теории перевода, чаще всего основанной на лингвистических моделях или на слабоструктурированных теориях литературоведения, и встраивая переводную литературу в широкий культурный контекст, Эвен-Зохар открыл для теории перевода возможность выйти за пределы прескриптивной эстетики» [Gentzler, 2001, p. 13].

В дальнейшем Левенская группа пришла к еще большей согласованности, учитывая исторический период. В 1970-е годы в научном мире Запада происходили масштабные сдвиги. Студенческие волнения 1968 г. привели к изменению учебных планов, и в то же время зародился целый ряд междисциплинарных предметов. Культурология, включавшая такие социологические понятия, как класс, раса, гендер; изучение кино и средств массовой информации, театроведение, феминистика - все они бросали вызов традиционному образованию, в частности делению литературы на высокую и низкую. К 1980-м годам эти предметные области превратились в полностью оформившиеся, полноправные дисциплины, отраженные 
в университетских программах, научных журналах, конференциях и крупных научно-исследовательских проектах. Трудно переоценить влияние на англоязычный мир в 1980-х годах таких ученых, как Альтюссер, Фуко, Барт, Сиксу, Кристева, Тодоров, Лотман, Деррида, и многих других, ставших известными благодаря переводам их трудов. Выдающийся британский шекспировед Т. Хокс пришел к мысли о разработке серии кратких введений к неохватному многообразию новых учений, появившихся в научном мире. Совместно с издательством “Methuen" (впоследствии эти книги перешли к "Routledge") он подготовил серию учебных пособий, известную как “New Accents” («Новое в науке»). Она открывалась его собственной книгой по структурализму и семиотике, затем последовали книги по гендерной политике, нарратологии, теории восприятия, деконструктивизму и многие другие, в частности первая публикация, представлявшая англоязычным читателям Левенскую группу - книга С. Басснетт “Translation Studies” («Переводоведение») (1980). В этой книге (четвертое издание вышло в 2014 г.) предлагается общий очерк новой области, который может оказаться полезным для тех, кто интересуется такими понятиями, как определение эквивалентности, находки и потери в переводе, непереводимость, а также затрагиваются основные проблемы литературного перевода и его роли в истории Европы. Монография содержит синтез традиционных представлений о переводе и новых точек зрения, выдвинутых Левенской группой. В ней обосновывается новые принципы переводоведения как области науки, оспаривающей общепринятые взгляды на перевод, в ряду множества других новых областей, сформировавшихся в 1980-е годы, включая постколониализм. Публикация этой книги в серии “New Accents" связала переводоведение с альтернативными культурными явлениями, бушевавшими по всей Европе и Северной Америке и бросавшими вызов традиционализму.

\section{Десятилетие экспансии: 1990-е годы}

Наивысшая фаза развития переводоведения пришлась на 1990-е годы. В начале этого периода существовало отчетливое расхождение между программами подготовки переводчиков, более всего связанными с теорией устного перевода, и только что сформировавшимся переводоведением. К настоящему времени это расхождение сошло на нет, и термин «переводоведение» в некоторых случаях относится и к программам подготовки переводчиков и обучения иностранным языкам, и к программам образования по литературоведению и лингвистике. Сказанное свидетельствует о глобальном интересе к изучению различных аспектов перевода, а также о том, что этот интерес существенно возрос в результате глобальных политических и экономических изменений в начале 1990-х годов. Распад Советского Союза, отмена апартеида в Южной Африке, налаживание отношений Китая с Западом, в результате чего миллионы людей получили возможность заняться международным туризмом, обусловили такие познавательные последствия, которые, в частности, выражаются и в растущем интересе к получению переводческого образования во всем мире. После 1990-х годов количество монографий, конференций, учебных программ и журналов увеличилось до такой степени, которую и представить себе не могли в 1970-х годах первые приверженцы переводоведения. Назову лишь несколько значимых специальных журналов, посвященных вопросам переводоведе- 
ния: Babel, Forum, Meta, Perspectives, TTR, Target, Translation Studies, Translation, The Translator, и этот список можно продолжить.

Не менее существенно и то, что в 1990-е годы произошла концептуализация перевода и понимание того, что он представляет собой нечто большее, чем просто передача языковых знаков. «Культурный переворот» в переводоведении, начатый Сьюзен Басснетт и Андре Лефевром, важен тем, что он подчеркнул необходимость в более целостном подходе к проблемам перевода и изучению тех двойственных контекстов, в рамках которых создается и оригинал, впоследствии называемый исходным текстом, и перевод, теперь известный как переводной текст. Этот культурный переворот был изначально сформулирован во введении к сборнику статей под общим названием “Translation, History and Culture” («Перевод, история и культура»). Басснетт и Лефевр доказывали, что следует уделять гораздо больше внимания культурным контекстам, в которых переводы создаются и в которых они принимаются. С точки зрения составителей сборника, переводоведение удаляется от формального подхода и обращается к более общим проблемам контекста, истории и условий. «Операциональной единицей» перевода является не слово и не текст, а целая культура: «Объект исследования был пересмотрен; теперь им стал текст, встроенный в сеть отношений между исходными и переводящими культурными знаками, и на этом пути переводоведение использовало не только лингвистический подход, но и вышло далеко за его пределы» [Bassnett and Lefevere, p. 12].

Основой культурного переворота стало представление о том, что перевод является пересозданием и что такое пересоздание возможно как на внутриязыковом, так и на межъязыковом уровне. Это дало возможность исследовать пути, по которым тексты пересоздаются и перечитываются в рамках одной культуры, а также подойти к переводу в более широком аспекте. Лефевр разработал эту представление о переводе как о пересоздании в книге 1992 г. "Translation, Rewriting and the Manipulation of Literary Fame” («Перевод, пересоздание и манипулирование литературной славой»), где он ставит перевод в общий ряд с такими явлениями, как историография, антологизация, литературная критика, редактирование, кино- и телеадаптация, и другими формами пересоздания, с которыми мы встречаемся постоянно. Он утверждал, что перевод является самой значимой из всех форм пересоздания, «поскольку он способен проецировать образ автора и его произведения (произведений) в иную культурную среду, расширяя границы восприятия этого автора и произведений за пределы породившей их культуры» [Lefevere, 1992, p. 9].

В качестве примера способности перевода воссоздавать образ автора в иноязычной культуре можно привести Чехова в английских переводах. Английский драматург и переводчик Майкл Фрейн заявил, что «можно не знать ни единого русского слова, чтобы перевести его пьесы, поскольку все знают, о чем пишет Чехов, и с большой долей уверенности представляют себе, что он намеревался сказать и что сказал» [Christopher Hampton..., p. 9]. Другие переводчики, например Елизавета Фен, напротив, доказывают, что Чехов - это сугубо русский писатель, но факт остается фактом: на английском языке Чехов главным образом воспринимается в контексте британской культуры. Недавно, в январе 2016 г., ВВС начал показ шестисерийного фильма по роману Толстого «Война и мир», снятого Эндрю Дейвисом, известным интерпретатором романов таких писателей, как Чарльз Диккенс, Джордж Элиот и Джейн Остин, и рецензенты уже отметили общность языка и об- 
разной интерпретации фильма «Война и мир» с произведениями Остин. Критики также утверждают, что сам роман нечитабелен, поскольку он слишком длинный потрясающее проявление английского антиинтеллектуализма!

Одним из наиболее спорных вопросов, часто обсуждаемых в переводоведении, остается вопрос о том, до какого предела может укорениться в принимающей культуре иностранный писатель. Лоренс Венути представил дихотомию между форинизацией и доместикацией, или аккультурацией, как проблему переводческой этики, интерпретируя Фридриха Шлейермахера для американского читателя. В книге “Тһе Translator's Invisibility: A history of translation” («Невидимость переводчика: история перевода»), ставшей одной из наиболее значительных публикаций в переводоведении, Венути утверждает, что в некоторых случаях перевод не только не способствует межкультурной коммуникации, но, напротив, становится насильственным актом. По его словам, перевод может оказаться «принудительной заменой языковой и культурной своеобычности оригинала текстом, вполне приемлемым для носителя переводящего языка» [Venuti, 1995, p. 18]. Такая принудительная замена является очевидным насилием со стороны доминантной культурно-языковой традиции, что нередко происходило в отношении языков и литератур, воспринимаемых как маргинальные или подчиненные доминантной культуре. Вопрос о неравноправии в переводе стал особенно актуальным для переводоведения в постколониальную эпоху, и такие ученые, как Теясвини Нираньяна, Кэрол Майер и Висенте Рафаэль, не говоря о многих других, обратили внимание на представление о переводе как об акте колониального присвоения, а не как о деятельности, основанной на равенстве партнеров. Ирландский переводчик и переводовед Майкл Кронин говорит о дисбалансе между английским как доминантным международным языком и ирландским, который расценивается в европейском сообществе как язык национального меньшинства. Кронин занимается переводом художественной и нехудожественной литературы, устным переводом и является автором целого ряда известных книг, в том числе “Translation and Globalization” («Перевод и глобализация») (2003) и “Translation in the Digital Age” («Перевод в эпоху цифровых технологий») (2013). В настоящее время Кронин редактирует новую серию книг для издательства "Routledge" под названием "New Directions in Translation Studies” («Новые направления в переводоведении»).

В предисловии к сборнику “Translation and Power” («Перевод и власть») его редакторы, Мария Тимочко и Эдвин Гентцлер, обращают внимание на политическую и познавательную роль перевода и, вслед за Басснетт и Лефевром, указывают на то, что перевод никогда не был «непорочной» деятельностью: «Таким образом, перевод занимается не просто отбором, монтажом, организацией и производством, а в некоторых случаях и фальсификацией, искажением, подделкой и разработкой секретных кодов. Во всех этих действиях переводчики, подобно писателям и политикам, участвуют в управлении обществом, формируя знания и культуру» [Tymoczko and Gentzler, p.xxii].

На неравноправие в переводе всегда обращают внимание переводоведы-феминисты, в частности франко-канадская школа, включая Шерри Саймон, Барбару Годард, Сюзанну де Лобиньер-Харвуд, Анни Бриссе и Луизу фон Флотов, - все они много пишут о женщинах-переводчиках и о становлении женской поэтики перевода. Особенно любопытно в исследованиях канадской школы то, что в ее рамках переводчики и переводоведы руководствуются идеями французского феминизма 
о ecriture feminine, чтобы выработать переводческую стратегию, известную как reecriture feminine, в которой отвергается традиционная оппозиция между исходным и переводным текстом и подчеркивается творческое начало в переводе. Барбара Годард побуждает женщин-переводчиц заявлять о своем присутствии в переводах, используя новый термин “woman-handling” (женское начало) как игру слов c "man-handling" (мужское начало), по отношению к физическому насилию: «Женщина-переводчик, утверждает свою особую сущность, наслаждается бесконечным перечитыванием и переписыванием, манипулируя текстом. Женское начало в переводном тексте выходит на первый план, вытесняя образ скромного, незаметного переводчика» [Godard, p.94].

Канадская школа внесла инновационные гендерные идеи в переводоведение, но не менее инновационные идеи о переводе постколониальной эпохи пришли из Индии и Бразилии. Особенно привлекла внимание бразильская «каннибальская теория», порожденная попытками бразильских писателей и интеллигенции переосмыслить отношения с Европой в свете собственной колониальной истории. В 1920-х годах группа бразильских писателей ухватилась за рассказ о том, как в XVI в. представители племени тупинамба убили и съели священника-миссионера. Этот акт каннибализма, рассматриваемый как абсолютное табу с точки зрения христиан-европейцев, в понимании тупинамба был знаком уважения, поскольку достойными поедания считались только значительные люди. Эта история о тупинамба была использована как образец переосмысливания отношений между бразильскими художниками и интеллигенцией в свете своего двойственного происхождения: они являются одновременно потомками и пожирателей, и пожираемых. Если Европа рассматривалась как образец, Оригинал, то колония могла быть только копией, Переводом этого всемогущего Оригинала, если не постараться переосмыслить это отношение путем «пожирания» Оригинала. Лишь поглотив Европу, колония могла отколоться от нее, а сам акт поглощения мог бы рассматриваться одновременно как разрушение культурного кода Европы и как проявление уважения, в результате чего возникнет нечто совершенно новое.

Применение «каннибальской теории» к переводу особенно заметно в творчестве Гарольдо и Аугусто де Кампосов, поэтов и переводчиков, на которых оказали сильное влияние идеи постмодернизма, в особенности Жак Деррида. Идеи Дерриды стали популярны в Латинской Америке, что сказалось не только на переводоведении, но и на литературном творчестве. В книге “Translation and identity in the Americas” («Перевод и идентичность в Америке») Эдвин Гентцлер отмечает, что в Латинской Америке литературное творчество тесно связано с переводом: «Перевод в теории, практике и художественной литературе, воссоздающей историю Латинской Америки, отражает самую суть латиноамериканской идентичности... Латиноамериканская художественная литература напоминает читателям о связях всех произведений с иностранными оригиналами и одновременно о собственной переводной природе» [Gentzler, 2008, p. 142].

Следует особо отметить, что исследователи перевода часто обращаются к творчеству таких писателей и переводчиков, как Хорхе Луис Борхес, Октавио Пас, Карлос Фуэнтес, Росарио Ферре, а известнейшие переводчики на английский язык не только переводят бразильскую и латиноамериканскую художественную прозу и поэзию, но и комментируют стратегии перевода. 
Параллельно с развитием переводоведения в области литературы в процессе метафорического использования терминов для обсуждения глобальной миграции, межкультурного обмена и, особенно, постколониальных явлений и проблем устоялся термин «культурный перевод», который не следует путать с культурным переворотом в переводоведении [Larsen et al.]. Понятие культурного перевода обычно связывается с именем Хоми Бхабха и его знаменитой статьей “How Newness Enters the World” («Как в мир приходит новизна»), в которой он изложил теорию промежуточности, «нового международного пространства дискретных исторических реальностей» [Bhabha, p.217]. Бхабха обращает внимание на то, что, поскольку в основе перевода лежит различие, задача переводчика сводится к преодолению крайне напряженного пространства между оригиналом и переводом. Действия в этом пространстве вынуждают переводчика к непосредственному обращению к тем аспектам текста, которые особенно сильно сопротивляются переводу, коротко говоря - к фактору непереводимости. Однако Бхабха имеет в виду не лингвистическую, а культурную непереводимость. С его точки зрения, феномен постколониальной миграции - это, по сути, проблема перевода, пространство, в котором смысл бесконечно обсуждается и воссоздается, в отличии от колониализма, для которого целью является распространение исходной культуры вовне. Так что идея новизны у Бхабха трактуется как новизна столкновения культур, лиминальности и гибридности, что он и обозначил термином «культурный перевод». Идеи Бхабха подвергаются критике за использование в его теории, в которой полностью игнорируется лингвистическая составляющая, термина «перевод», тем не менее это использование термина в метафорическом смысле для обозначения смещения и столкновения культур оказало и продолжает оказывать значительное влияние на североамериканское литературоведение.

\section{Переводоведение в XXI веке}

Развитие переводоведения как самостоятельной области науки привело к открытию новых направлений исследования. В рамках данной статьи не представляется возможным перечислить все, но можно назвать изучение переводческих норм и связь между переводом и преобладающими в тот или иной исторический период эстетическими критериями, что закономерно вовлекает стилистический анализ с учетом различных исторических контекстов, наряду с изучением меняющегося статуса переводчика и перевода, а также места, занимаемого переводами в национальных литературных традициях. Гендерные исследования в переводоведении расширились от феминистского фактора до учета гомосексуально-лесбиянского перевода, и в этом направлении существуют интересные наблюдения в связи с проблемой перевода в условиях сопоставления гендерно-обусловленных языков (например, итальянский или испанский), имеющих грамматическую категорию рода, и гендерно-необусловленных (например, английский). Вопросы пола и власти привели к исследованию изменчивости переводческой этики, а также отношений между переводом и цензурой. Последнее направление особенно любопытно, так как цензура не только определяет, какие тексты можно переводить в определенный исторический момент, но и то, как манипулировать оригиналами, то есть заставляя перевод удовлетворять требованиям цензуры. Кристофер Рандл, наряду 
с другими исследователями, сопоставил использование дубляжа, начиная с 1930-х годов, особенно в странах с тоталитарными режимами, и субтитров, предпочитаемых в других странах и обеспечивающих зрителям доступ к языку оригинала. Аудиовизуальный перевод, субтитры и надтитры (sur-titling) все активнее входят в область интересов переводоведения.

Основанное на теориях Пьера Бурдье и Жан-Марка Гуваника, новое направление в переводоведении, а именно социология перевода, приобретает растущую популярность. С этим направлением связано изучение перевода политического дискурса и соответствующих идеологических импликаций. Кристина Шефнер, одна из ведущих исследователей в этой области, поставила перед переводоведами ряд вопросов: «Что именно происходит в процессе перехода от исходного политического дискурса с его национально-политическим укладом к его репрезентации в иноязычных средствах массовой информации в другой стране? Кто именно вовлечен в этот процесс? Кто и какие решения принимает при передаче того или иного смысла? Как все эти сложные процессы отражаются в текстах? ...Как можно объяснить и оправдать такие трансформации? Какое воздействие они оказывают на получателя и его восприятие политических событий?» [Schaeffner and Bassnett, p. 21].

Похожие вопросы возникают в связи с переводом глобальных новостей, что тем более актуально из-за ожиданий пользователей телевидения и интернета, которые хотят получать новости в течение двадцати четырех часов. В этой области одним из ведущих специалистов является Эсперанса Бьелса; в книге 2009 г. "Globalization, Political Violence and Translation” («Глобализация, политическая власть и перевод»), соредактором которой она являлась вместе с К. У.Хьюзом, Бьелса называет перевод ключевым компонентом глобализации, поскольку он «обеспечивает взаимодействие между глобальным и местным» [Bielsa and Hughes, p. 15]. Все эти направления в основном исходят из сформулированного Лефевром и Холмсом положения о том, что изучение перевода должно сочетать микро- и макроэлементы, текстуальный и контекстуальный анализ.

Среди интереснейших объектов исследований литературного перевода можно назвать самоперевод, когда писатель сам создает произведение на двух и более языках, а также псевдоперевод - термин, использованный Г. Тури для случаев, когда автор называет свой текст переводом, хотя на самом деле это не перевод: и в том и другом случае автор, он же переводчик, вправе распоряжаться собственным произведением. Во введении к сборнику статей "Self-Translation: Brokering Originality in Hybrid Culture” («Самоперевод: Оригинальное посредничество в гибридной культуре») Энтони Кордингли отмечает, что самопереводчики позволяют себе такие вольности, о которых другие переводчики и помыслить не смеют: самоперевод обычно создает еще один «вариант» или новый «оригинал» текста. При этом оказывается сомнительным не только «оригинальный» текст или авторство того, кто его создал, но и само представление об оригинальности [Cordingley, p. 2].

Исследования самоперевода и псевдоперевода - это области, в которых интересы переводоведения соприкасаются с литературоведением и историей всемирной литературы. В этих трех различных, но взаимосвязанных науках продолжается дискуссия о сути оригинальности и отношениях между текстами оригинала и перевода. В 1971 г. Октавио Пас опубликовал статью, в которой утверждал, что все 
тексты в той или иной степени связаны друг с другом, и хотя каждый из них претендует на уникальность, на самом деле полностью оригинальных текстов не существует, поскольку все они являются «переводами переводов переводов» [Paz, p. 154]. Идея Паса чрезвычайно плодотворна для представления о творческом характере перевода и его важной роли в становлении литературных традиций, и любопытно отметить, что параллельно и одновременно с ней развивались идеи Левенской группы, обусловившие становление переводоведения как самостоятельной науки. В настоящее время все больше укореняется представление о творческой природе переводческого труда: как воссоздатель исходного текста, порожденного другой культурой, он, в свою очередь, создает новый «оригинал» в принимающей культуре.

Одно из самых значимых замечаний о важности перевода в наше время сделано американским литературоведом Беллой Бродски. В своей книге "Сan These Bones Live? Translation, Survival and Cultural Memory” ( Оживут ли кости сии? Перевод, жизнеспособность и культурная память») она отмечает, что по мере становления международного статуса английского языка и ослабления интереса к изучению иностранных языков в англоязычном мире становится как никогда необходимо осознать значение и важность перевода не только как способа создания культурных объектов, но и как инструмента для развития международных отношений, массового туризма, науки и техники. Она считает, что переводы вплетены в обширную сеть межъязыковых контактов, культурных событий и различных точек зрения. Перевод участвует в культурных событиях во всем мире, и Бродски даже утверждает следующее: как невозможно в наши дни представить себе без участия гендерного фактора такие понятия, как авторство, посредничество, субъективность, исполнительство, мультикультурализм, постколониализм, транснационализм, национальная и технологическая грамотность, так невозможно пренебречь представлением о переводе как естественной составляющей любого дискурса [Brodzki, c. 2].

Бродски обращается к Северной Америке, все более заметно тяготеющей к моноязычию, и может показаться, что она заходит слишком далеко. Однако она справедливо подчеркивает необходимость воспринимать перевод всерьез, изменить представление о переводе только как о межъязыковом перекодировании и воздать должное переводу и переводчикам. Ее мысли разделяет Л. Венути, и в своей книге “Translation Changes Everything. Theory and Practice” («Перевод меняет все. Теория и практика») (2013) он заявляет о становлении того, что он называет культурой перевода.

Не вызывает сомнений, что перевод стал весомым фактором в условиях глобализации в XXI в. Нет сомнений и в том, что переводоведение, в 1970-х годов представлявшее собой исходный комплекс идей, выдвинутых небольшой международной группой ученых, которых не устраивало маргинальное положение теории перевода в лингвистике и литературоведении и которые просто хотели открыть новые подходы к представлению о создании и передаче текстов в условиях межъязыковых и межкультурных ограничений, развивается и обретает отчетливые очертания.

References

Bassnett S. Translation. London, New York, Routledge Publ., 2014. 201 p.

Bassnett S. Translation Studies. $4^{\text {th }}$ ed. London, New York, Routledge Publ., 2014. 202 p. 
Bhabha H. K. The Location of Culture. London, New York, Routledge Publ., 1994. 298 p.

Bielsa E. Translation in Global News. Eds. E. Bielsa, S. Bassnett. London, New York, Routledge Publ., 2009. $162 \mathrm{p}$.

Brodzki B. Can These Bones Live? Translation, Survival and Cultural Memory. Stanford, Stanford Univ. Press, 2007. $272 \mathrm{p}$.

Cordingley A. Self-Translation. Brokering Originality in Hybrid Culture. London, New York, Bloomsbury Publ., 2013. 211 p.

Christopher Hampton, Jeremy Sams, Michael Frayn, Ranjit Bolt, Steven Pimlott, Timberlake Wertenbaker in a discussion chaired by Colin Chambers. Platform Papers 1. Translation. London, Royal National Theatre Publ., 1992.

Cronin M. Translation and Globalization. London, New York, Routledge Publ., 2013. 197 p.

Cronin M. Translation in the Digital Age. London, New York, Routledge Publ., 2013. 174 p.

Even-Zohar I. The Position of Translated Literature in the Literary Polysystem. The Translation Studies Reader. Ed. by L. Venuti. London, New York, Routledge Publ., 2000, pp. 192-197.

Gentzler E. Contemporary Translation Theories. $2^{\text {nd }}$ ed. Clevedon, Multilingual Matters Publ., 2001. 232 p.

Gentzler E. Translation and Identity in the Americas: New Directions in Translation Theory. London, New York, Routledge Publ., 2008. 231 p.

Globalization, Political Violence and Translation. Eds. E. Bielsa, C. W. Hughes. London, Palgrave Macmillan Publ., 2009. $271 \mathrm{p}$.

Godard B. Theorizing Feminist Discourse/Translation. Translation, History and Culture. Eds. S. Bassnett, A. Lefevere. London, Pinter Publ., 1990, pp. 87-106.

Holmes J. Translated! Papers on Literary Translation and Translation Studies. Amsterdam, Rodopi Publ., 1988. $117 \mathrm{p}$.

Holmes J. The Name and Nature of Translation Studies. The Translation Studies. Reader. Ed. by L. Venuti. London, New York, Routledge Publ., 2000, pp. 172-185.

Larsen S. E., Bassnett S., Segal N., Thomsen M.R., Baetens J., Lombardo P., D’haen T. Future without Humanities: Literary Perspectives. Humanities. 2015, vol.4 (1), pp.131-148. DOI: 10.3390/h4010131. Available at: http://www.mdpi.com/2076-0787/4/1/131/htm (accessed: 23.06.2016).

Lefevere A. Translation Studies: The Goal of the Discipline. Literature and Translation: New Perspectives in Literary Studies Eds. J.Holmes, J.Lambert, R.van de Broek. Leuven, Academic Publ. Co., 1978, pp. 234-235.

Lefevere A. Translation, Rewriting and the Manipulation of Literary Fame. London, New York, Routledge Publ., 1992. 184 p.

Munday J. Introducing Translation Studies: Theories and Applications. 1st ed. 2001. London, New York, Routledge Publ., 2013. 236 p.

Paz O. Translation, Literature and Letters. Theories of Translation: An Anthology of essays from Dryden to Derrida. Eds. R. Schulte, J. Biguenet, trans. I.del Corral. Chicago, Univ. of Chicago Press, 1992, pp. 152-162.

Political Discourse, Media and Translation. Eds. C. Schaeffner, S. Bassnett. Newcastle-upon-Tyne, Cambridge Scholars Publ., 2010. 254 p.

Popovic A. The Concept of Shift of Expression in Translation Analysis. The Nature of Translation. Eds. J.Holmes, F. de Haan, A. Popovic. The Hague, Mouton Publ., 1970, pp. 78-87.

Postcolonial Translation. Theory and Practice. Eds. S. Bassnett, H. Trivedi. London, New York, Routledge Publ., 1999. 201 p.

Rundle C. Publishing Translations in Fascist Italy. Oxford, Peter Lang Publ., 2010. 268 p.

Simon S. Gender in Translation: Cultural identity and the Politics of Transmission. London, New York, Routledge Publ., 1996. 205 p.

Toury G. Descriptive Translation Studies and Beyond. Amsterdam, Philadelphia, John Benjamins Publ., 1985. $319 \mathrm{p}$.

Toury G. A Rationale for Descriptive Translation Studies. The Manipulation of Literature. Ed. by T. Hermans. London, Croom Helm Publ., 1985, pp. 16-41.

Translation and Power. Eds. M. Tymoczko, E. Gentzler. Amherst, Boston, Univ. of Massachusetts Press, 2002. $272 \mathrm{p}$.

Translation History and Culture. Eds. S. Bassnett, A. Lefevere. London, Pinter Publ., 1990. 141 p.

Venuti L. The Translator's Invisibility: A history of translation. London, New York, Routledge Publ., 1995. $365 \mathrm{p}$. 
Venuti L. Translation Changes Everything: Theory and Practice. London, New York, Routledge Publ., 2013. $281 \mathrm{p}$.

Для цитирования: Басснетm С. Истоки и развитие переводоведения в 1975-2016 гг. // Вестник СПбГУ. Серия 9. Филология. Востоковедение. Журналистика. 2016. Вып. 4. С. 31-44. DOI:

For citation: Bassnett S. The Origins and Development of Translation Studies 1975-2016. Vestnik SPbSU. Series 9. Philology. Asian Studies. Journalism, 2016, issue 4, pp. 31-44. DOI: 10.21638/11701/spbu09.2016.403.

\section{Статья поступила в редакцию 15 февраля 2016 г.}

Статья рекомендована в печать 30 мая 2016 г.

Контактная информация :

Басснетт Сьюзен - профессор сравнительного литературоведения; S. Bassnett@warwick.ac.uk, Susan.Bassnett@glasgow.ac.uk

Bassnett Susan - Professor of Comparative Literature; S. Bassnett@warwick.ac.uk,

Susan.Bassnett@glasgow.ac.uk 